University of Nebraska - Lincoln

DigitalCommons@University of Nebraska - Lincoln

$12-7-2018$

\title{
Weekly Survivorship Curves of Soybean Aphid Biotypes 1 and 4 on Insecticidal Seed-Treated Soybean
}

\author{
Carlos J. Esquivel \\ Ohio State University \\ Christopher M. Ranger \\ Ohio State University \& USDA-Agricultural Research Service \\ P. Larry Phelan \\ Ohio State University \\ Erick J. Martinez \\ Ohio State University \\ William $\mathrm{H}$. Hendrix \\ Valent U.S.A. LLC
}

See next page for additional authors

Follow this and additional works at: https://digitalcommons.unl.edu/usdaarsfacpub

Esquivel, Carlos J.; Ranger, Christopher M.; Phelan, P. Larry; Martinez, Erick J.; Hendrix, William H.; and Michel, Andrew P., "Weekly Survivorship Curves of Soybean Aphid Biotypes 1 and 4 on Insecticidal SeedTreated Soybean" (2018). Publications from USDA-ARS / UNL Faculty. 2145.

https://digitalcommons.unl.edu/usdaarsfacpub/2145

This Article is brought to you for free and open access by the U.S. Department of Agriculture: Agricultural Research Service, Lincoln, Nebraska at DigitalCommons@University of Nebraska - Lincoln. It has been accepted for inclusion in Publications from USDA-ARS / UNL Faculty by an authorized administrator of DigitalCommons@University of Nebraska - Lincoln. 


\section{Authors}

Carlos J. Esquivel, Christopher M. Ranger, P. Larry Phelan, Erick J. Martinez, William H. Hendrix, and Andrew P. Michel 


\title{
Weekly Survivorship Curves of Soybean Aphid Biotypes 1 and 4 on Insecticidal Seed-Treated Soybean
}

\author{
Carlos J. Esquivel, ${ }^{1}$ Christopher M. Ranger, ${ }^{1,2}$ P. Larry Phelan, ${ }^{1}$ Erick J. Martinez, ${ }^{1}$ \\ William H. Hendrix, ${ }^{3}$ Luis A. Canas, ${ }^{1}$ and Andrew P. Michel ${ }^{1,4,5}$
}

\begin{abstract}
'Department of Entomology, Ohio Agricultural Research and Development Center, The Ohio State University, Wooster, $0 \mathrm{H} 44691$, ${ }^{2}$ Horticultural Insects Research Lab, USDA-Agricultural Research Service, Wooster, OH 44691, ${ }^{2}$ Valent U.S.A. LLC, Walnut Creek, CA 94596, and ${ }^{4}$ Center of Applied Plant Sciences, The Ohio State University, Wooster, $\mathrm{OH} 44691,{ }^{5}$ Corresponding author, e-mail: michel.70@osu.edu
\end{abstract}

Subject Editor: Dominic Reisig

Received 22 August 2018; Editorial decision 7 December 2018

\begin{abstract}
Thiamethoxam, an insecticide used in soybean seed treatments, effectively suppresses soybean aphids (Aphis glycines) Matsumura (Hemiptera: Aphididae) for a short time after planting. However, exactly when and how quickly soybean aphid populations could increase is unknown. Likewise, we lack data on virulent soybean aphid biotypes (that can overcome soybean resistance) when fed on seed-treated soybean. Determining the survival of soybean aphids over time on insecticidal seed-treated soybean is critical for improving soybean aphid management and may provide insights to manage aphid virulence to aphid resistant-soybean. In greenhouse and field experiments, aphid-susceptible soybean plants (with and without an insecticidal seed treatment) were infested at 7, 14, 21, 28, 35, and 42 days after planting (DAP). We compared aphid survival among biotypes 1 (avirulent) and 4 (virulent) and insecticide treatment $72 \mathrm{~h}$ after infestation. We also measured thiamethoxam concentrations in plant tissue using liquid chromatography-tandem mass spectrometry. As expected, soybean aphid survival was significantly lower on seed-treated soybean up to 35 DAP for both biotypes, which correlates with the decrease of thiamethoxam in the plant over time. Moreover, we found no significant difference between avirulent and virulent biotype survivorship on insecticidal seed-treated soybean plants, although we did find significantly greater survival for the virulent biotype compared with the avirulent biotype on untreated soybean in the field. In conclusion, our study further characterized the relative short duration of seed treatment effectiveness on soybean aphid and showed that survivorship of virulent aphids on seed-treated soybean is similar to avirulent aphids.
\end{abstract}

Key words. soybean aphid, thiamethoxam, seed treatment, soybean, UPLC-MS/MS

Insecticidal seed treatments provide early season control of insect pests in several crops (Wilde et al. 2001, 2004, 2007; Hummel et al. 2014; Schmidt-Jeffris and Nault 2016). More than $40 \%$ of soybean planted in 2011 had an insecticidal seed treatment (Douglas and Tooker 2015), and this percentage has likely grown (Hurley and Mitchell 2017) for various reasons, including their easy use and efficacy against target pests. In soybean, these pests include not only a few soil insects, e.g., wireworms (Coleoptera: Elateridae) and seedcorn maggot (Delia platura) (Meigen) (Diptera: Anthomyiidae), but also early season foliar feeders, such as the bean leaf beetle (Cerotoma trifurcata) (Föster) (Coleoptera: Chrysomelidae) and the soybean aphid (Aphis glycines) Matsumura (Hemiptera: Aphididae) (Hesler et al. 2018). Damage from foliage-feeding insects occurs throughout the growing season and may indeed be heavier later in the season
(Krell et al. 2004, Rutledge and O'Neil 2006). However, the protection provided by insecticidal seed treatments is short lived, ranging from 3 to 8 wk after planting, depending on experimental conditions (McCornack and Ragsdale 2006, Seagraves and Lundgren 2012, McCarville and O’Neal 2013, Krupke et al. 2017). A more complete understanding of the timing between insecticidal seed treatment efficacy and pest survival is needed to improve integrated pest management in soybean, including for the soybean aphid, which is the most important insect pest of soybean in the North-Central region (Tilmon et al. 2011).

The soybean aphid is an invasive pest, infesting soybean as early as the first week of June (V1-V3 based on Fehr et al. 1971), where it asexually reproduces for $>15$ generations (Ragsdale et al. 2004). Soybean aphid densities exceeding 600 aphids per plant cause 
economically significant yield losses to soybean (Ragsdale et al. 2007) and heavy infestations can exceed thousands of aphids per plant (Ragsdale et al. 2004). In North America, insecticide applications to soybean have increased 130 -fold since the invasion of soybean aphid in 2000 (Ragsdale et al. 2011). Foliar applications are the most common, but insecticide resistance to some of the more generally used chemicals (e.g., pyrethroids) limits soybean aphid management options (Hanson et al. 2017, Koch et al. 2018).

Seed treatment for soybean aphid control can include one of the three active ingredients: imidacloprid, clothianidin, and thiamethoxam (all within IRAC Group 4A) (Hodgson et al. 2012), with the latter being the most widely used (U.S. Geological Survey 2014). Field studies (McCarville and O’Neal 2013, Krupke et al. 2017) and laboratory bioassays (McCornack and Ragsdale 2006, Magalhaes et al. 2009, Seagraves and Lundgren 2012) indicate that insecticidal seed treatments can provide control against the soybean aphid up to 40-49 days after planting (DAP). Loss of activity corresponds to a decrease in thiamethoxam concentration in soybean tissue (Magalhaes et al. 2009, Krupke et al. 2017). However, we lack data on aphid survivorship at early time points, especially during the critical time when the concentration of seed treatments decreases to negligible levels (between 14 and 42 DAP). Estimating survivorship of soybean aphid on insecticidal seed-treated soybean early in the growing season could enhance our understanding of soybean aphid population dynamics and improve integrated pest management.

Another option for soybean aphid control includes aphidresistant soybean varieties (Hesler et al. 2013). Rag (Resistance to Aphis glycines) soybean varieties have genetic resistance against the soybean aphid. In total, eight Rag genes have been mapped (Hesler et al. 2013) and soybean varieties with Rag1, Rag2, or both (Rag1/ Rag2) are commercially grown (McCarville et al. 2012). McCarville and O'Neal (2013) showed that an insecticidal seed treatment might enhance soybean aphid control in combination with single Rag gene soybeans (e.g., Rag1 or Rag2), but it provides little added benefit with multigenic resistant varieties (e.g., Rag1/Rag2), since the effect of multiple Rag genes is a 'high-dose' for most aphid populations.

Virulent biotypes of soybean aphid, however, have overcome Rag resistance including varieties that contain Rag1/Rag2 (Kim et al. 2008). Currently, there are at least four soybean aphid biotypes: biotype 1 is susceptible or avirulent to any Rag gene, biotype 2 is virulent to Rag1, biotype 3 is virulent to Rag2, and biotype 4 is virulent to Rag1, Rag2, and Rag1/Rag2 genes (Kim et al. 2008, Hill et al. 2010, Alt and Ryan-Mahmutagic 2013). Unless strategies are developed to manage virulence similar to insecticide resistance management (IRM) in transgenic crops, virulent soybean aphid biotypes will threaten the durability of Rag soybean. Typically, a virulence management strategy for asexually reproducing aphids would require a fitness cost, where a virulent aphid is less fit than an avirulent aphid on a susceptible plant (Crowder and Carriere 2009). Indeed, Rag virulence in biotype 4 appears to have a fitness cost compared with biotype 1 (Varenhorst et al. 2015), but there is little information comparing survival among biotypes on seed-treated soybean. If Rag soybean is treated with an insecticidal seed treatment and planted with an untreated susceptible refuge, the durability of resistance to soybean aphid might be extended if avirulent biotypes outperform virulent biotypes on untreated susceptible soybean (i.e., the refuge) as in other systems (Roush 1998, Petzold-Maxwell et al. 2013). We must understand the fitness of different soybean aphid biotypes on insecticidal seed-treated plants to determine what role, if any, these tools can have for IRM with aphid-resistant soybean.

Using greenhouse and field experiments, we estimated soybean aphid survival over $42 \mathrm{~d}$ for both biotype 1 (avirulent) and biotype
4 (virulent). We infested treated and untreated susceptible soybean at six different time points and measured aphid survival as well as foliar concentrations of thiamethoxam. We hypothesized that soybean aphid survival and thiamethoxam concentrations would be negatively correlated. We also hypothesized that biotype 1 would have similar fitness to biotype 4 on insecticidal seed-treated soybean, and higher fitness than biotype 4 on untreated soybean, which might support the use of seed treatments in IRM for Rag genes.

\section{Materials and Methods}

\section{Soybean Seeds}

We used Mycogen (Dow AgroSciences, Indianapolis, IN) variety 5N248R2 (aphid-susceptible), treated with Cruiser Maxx (Syngenta, Greensboro, NC) containing thiamethoxam (56.3 g of active ingredient), and two fungicides, mefenoxam (3.75 g of active ingredient), and fludioxonil (2.5 g of active ingredient) per $100 \mathrm{~kg}$ of seed. For untreated seeds, we removed the seed coating following a modified protocol from Gassmann et al. (2011). Briefly, in total, 120 seeds were processed three times with $200 \mathrm{ml}$ of deionized water and $1 \mathrm{ml}$ of dish liquid soap Dawn (Procter \& Gamble, MI), each time stirring for $20 \mathrm{~min}$ at $125 \mathrm{rpm}$. Seeds were then washed with $200 \mathrm{ml}$ of a $1 \%$ bleach solution stirred at $125 \mathrm{rpm}$ for $40 \mathrm{~min}$, followed by rinsing 10 times with deionized water. Removal of insecticide was confirmed by ultra-performance liquid chromatography mass spectrometry (UPLC-MS/MS, see below).

\section{Soybean Aphids}

For all experiments, we used 7-d-old adult apterae of both biotype 1 and biotype 4 soybean aphids. Aphids were kept in the Michel Laboratory at the Ohio Agricultural Research and Development Center (OARDC), The Ohio State University, Wooster, Ohio. Colonies were maintained in growth chambers at $26^{\circ} \mathrm{C}, 14: 10$ (L:D) $\mathrm{h}$, and $50 \% \mathrm{RH}$. Biotype 1 aphids were reared on susceptible soybean (variety Wyandot), whereas biotype 4 were reared on Rag1/ Rag2 soybean (variety IA3027RA12). Colonies were established with a single, founding aphid female, resulting in two clonal lineages. We age-synchronized aphids of both biotypes by transferring adults to detached, susceptible soybean leaves in Petri dishes. Adults were removed after $48 \mathrm{~h}$, leaving behind nymphs that were then maintained until they reached adulthood (7-d-old) for infestation.

\section{Greenhouse Experiments}

Greenhouse experiments, initiated in December of 2015 and October 2016, were maintained at $23-25^{\circ} \mathrm{C}, 16: 8$ (L:D) h, and 60-75\% RH, using an Argus Control System-a Conviron Company (British Columbia, Canada). Three soybean seeds of either insecticide-treated or untreated were planted in a Kord Regal (Toronto, Canada) pot (10.1-cm upper diameter, 7.6-cm lower diameter, 8.9-cm height) filled with soilless media Pro-Mix BX (Québec, Canada). Pots were arranged in a randomized complete block design. We watered soybean using drip irrigation with the following schedule: 1) days 0-15, $60 \mathrm{ml}$ per pot four times per week; 2) days $16-27,90 \mathrm{ml}$ per pot per day; 3 ) days $28-38,60 \mathrm{ml}$ per pot two times per day; and 4) days $39-42,90 \mathrm{ml}$ per pot two times per day. Fertilization was also included via irrigation by diluting, in a 1:64 ratio, a solution of $121.13 \mathrm{~g} \mathrm{~N}, 52.49 \mathrm{~g} \mathrm{P}_{2} \mathrm{O}_{5}$, and $121.13 \mathrm{~g} \mathrm{~K}_{2} \mathrm{O}$ in 7.57 liters of water.

Pots with soybeans were arranged using a factorial randomized complete block design. The factors were as follows: 1) aphid biotype: biotype 1 and biotype $4 ; 2$ ) seed treatment: treated-seed and untreated; and 3) plant age: 7, 14, 21, 28, 35, and 42 DAP. Treatments 
were replicated 10 times for each greenhouse experiment. We infested soybeans at six plant ages: 7, 14, 21, 28, 35, and 42 DAP. At each time point, we thinned soybeans to one plant per pot and transferred 10 synchronized adult aphids to the newest, fully mature middle leaflet using a fine-haired paintbrush. Transferred aphids were confined to the corresponding leaf using customized polyethylene terephathalate plastic cages $(1.9-\mathrm{cm}$ diameter, $1.9-\mathrm{cm}$ height, with Casa Collection [South Korea], polyester mesh 'U.S. \#100' on top) glued to an 8.8-cm metallic hair clip for leaf attachment. Aphid survival was measured 24,48 , and $72 \mathrm{~h}$ after infestation. Dead aphids were those that were brown or showed no movement when touched with a paintbrush.

\section{Field Experiment}

The field experiment was performed at OARDC $\left(40^{\circ} 46^{\prime} 56.8^{\prime \prime} \mathrm{N}\right.$; $\left.81^{\circ} 55^{\prime} 27.3^{\prime \prime} \mathrm{W}\right)$. The soil in the soybean field was Wooster Riddles silt loam ( $17 \%$ sand, $70 \%$ silt, $13 \%$ clay), with $1.79 \%$ of organic matter, and no history of neonicotinoid exposure for the last 5 years. During the experiment (20 June-5 August 2017), temperature ranged from 27.3 to $15.9^{\circ} \mathrm{C}$ and had a total of $182.2 \mathrm{~mm}$ of precipitation. Seed material and seed treatment were the same types used in greenhouse experiments. Seeds were planted using a split-plot design due to restrictions in randomization between treated and untreated seeds. The main plots were seed treatment (treated and untreated) and the experimental units (subplots) were the combination of aphid biotypes (biotype 1 and biotype 4) and plant ages (7, 14, 21, 28, 35 , and 42 DAP) for aphid infestation. The main plots were $1.2 \mathrm{~m}$ apart. Subplots were $40 \mathrm{~cm}$ between rows and $30 \mathrm{~cm}$ within the row. Treatments were replicated 10 times. We planted three seeds per experimental unit and then thinned to just one plant before infestation. Due to dry environmental conditions, subplots were watered every other day during the first 10 DAP. Aphid infestation with clip cages and survival measurement were performed as previously described for the greenhouse experiment.

\section{Aphid Survival}

We analyzed aphid survival $72 \mathrm{~h}$ after infestation to ensure that mortality was not due to handling of aphids. (Note: survival at 24 and $48 \mathrm{~h}$ is reported in Supp Figs. 1 and 2 [online only].) Survival for the 2015 and 2016 greenhouse experiments were analyzed separately. We evaluated normality and homoscedasticity of raw and arcsine-transformed greenhouse and field data using RStudio (version 1.0.136). We used raw data for statistical analysis as we found them normally distributed and with homogeneous variances. Analysis of variance (ANOVA) was used to evaluate the effects on aphid survival (percentage of aphids alive) from the seed treatment (i.e., treated and untreated seeds), plant age $(7,14,21,28,35$, and 42 DAP), and their interactions. We performed mean separation using Tukey's HSD test with a $95 \%$ family-wise confidence level on main factors and least square means with Tukey's adjustment on significant interactions $(P<0.05)$. We further estimated the effects of soybean age on aphid survival by an analysis of covariance (ANCOVA) using DAP as a continuous covariant. ANOVA and ANCOVA were performed using SAS software (version 9.4) for greenhouses and field experiments. Graphics were generated using GraphPad Prism (version 6) GraphPad Software Inc. (La Jolla, CA).

\section{Plant Tissue Sampling and Extraction}

After recording aphid survival at $72 \mathrm{~h}$, the infested leaf and all the younger foliage were flash frozen using liquid nitrogen and stored at $-80^{\circ} \mathrm{C}$ until we performed analysis by UPLC-MS/MS. Leaves were collected from both treated and untreated plants at each time point. For chemical analysis, frozen soybean samples were dried at $70^{\circ} \mathrm{C}$ in an oven for $48 \mathrm{~h}$. We placed $1.5 \mathrm{~g}$ of ground dry plant material into a $50 \mathrm{ml}$ tube with $10 \mathrm{ml}$ of $1 \%$ acetic acid solution in acetonitrile $(\mathrm{v} / \mathrm{v})$, containing $15 \mu \mathrm{g}$ of triphenyl phosphate (TPP) as an internal standard. Tissue samples were cleaned using the Restek Q-sep (Bellefonte, PA) QuEChERS method (Anastassiades et al. 2003), following the manufacturer's protocols. In short, $6 \mathrm{~g}$ magnesium sulfate and $1.5 \mathrm{~g}$ anhydrous sodium acetate were added to each test tube. The tube was vortexed for $1 \mathrm{~min}$ and then centrifuged for $1 \mathrm{~min}$ at 3,000 rpm. The top layer $(1 \mathrm{ml})$ was transferred to a dispersive solid-phase extraction (dSPE) tube for further cleaning based on the AOAC 2007.01 method (Horwitz 2000). The dSPE tube contained $150 \mathrm{mg}$ magnesium sulfate, $50 \mathrm{mg}$ primary-secondary amine, and $50 \mathrm{mg}$ of $\mathrm{C}_{18}$ sorbent. The dSPE tube was vortexed for $30 \mathrm{~s}$ and centrifuged for $1 \mathrm{~min}$ at 3,600 rpm. A $600 \mu \mathrm{l}$ aliquot from each test tube was transferred to a $12 \times 32 \mathrm{~mm}$ Waters autosampler vial (Milford, MA). The extracts were evaporated and dried using nitrogen at $55^{\circ} \mathrm{C}$. Residues were reconstituted in $600 \mu \mathrm{l}$ of ultra-pure water and transferred to a new autosampler vial for analysis by UPLC-MS/MS.

\section{Insecticide Quantification by UPLC-MS/MS}

Thiamethoxam quantification was performed using an Acquity UPLC system coupled to a Xevo TQD tandem quadrupole mass spectrometer (Waters Corp.). The UPLC was equipped with an Acquity $\mathrm{BEH} \mathrm{C}_{18}$ column $(1.7 \mu \mathrm{m}$ particle size, $50 \times 2.1 \mathrm{~mm})$ maintained at $40^{\circ} \mathrm{C}$. The mobile phases consisted of (A) $0.1 \%$ formic acid and $5 \mathrm{mM}$ ammonium formate in ultra-pure water and (B) $0.1 \%$ formic acid and $5 \mathrm{mM}$ ammonium formate in acetonitrile at a flow rate of $0.18 \mathrm{ml} / \mathrm{min}$. The following mobile phase parameters were used: $0-2.5 \mathrm{~min}: 100 \%$ A to $60 \% \mathrm{~A} ; 2.5-3.5 \mathrm{~min}: 60 \%$ A to $0 \%$ A; $3.5-4.5 \mathrm{~min}: 0 \% \mathrm{~A}$; $4.5-5.0 \mathrm{~min}$ : $0 \%$ to $100 \% \mathrm{~A}$; and $5.0-8.0$ min: $100 \%$ A. The injection volume was $5 \mu$ l. The mass spectrometer was operated in positive electrospray ionization mode using a source temperature of $150^{\circ} \mathrm{C}$. The nitrogen desolvation gas flowed at a rate of 540 liter/h and a temperature of $150^{\circ} \mathrm{C}$. Multiple reaction monitoring was used to measure parent and product ions for thiamethoxam and TPP (Supp Table 1 [online only]). The primary and secondary ion transition were determined using the IntelliStart function in MassLynx software (Waters Micromass, Manchester, United Kingdom), by directly infusing $0.5 \mathrm{mg} / \mathrm{ml}$ of standard solutions at a rate of $5 \mu \mathrm{l} / \mathrm{min}$. The IntelliStart function was also used to determine the optimal cone voltage and collision energy for the primary and secondary ion transitions (Supp Table 1 [online only]).

\section{Results}

\section{Greenhouse Experiment}

On untreated soybean, survival of biotype 1 ranged from 63 to $88 \%$, across all time points and among years, whereas biotype 4 survival ranged from 46 to $92 \%$ (Fig. 1). There were neither significant differences among biotype survival (Tables 1 and 2), nor observable fitness costs (i.e., survival) with biotype 4 among years. In the 2016 experiment only, biotype 1 and biotype 4 soybean aphid survival showed a significant parallel decreasing slope in response to plant age (slope: $-0.7082 \pm 0.13, P<0.05$ ) (Table 3 ).

In contrast, aphids feeding on seed-treated soybean showed a sigmoidal curve in response to plant age. Sigmoidal curves were visually categorized in three sections according to their slopes: 7-21, 21-35, and $\geq 35$ DAP. Survival at 7-21 DAP showed an average of $1 \%$ survival with no rapid increase, whereas survival at 21-35 DAP sharply rose up to 
2015

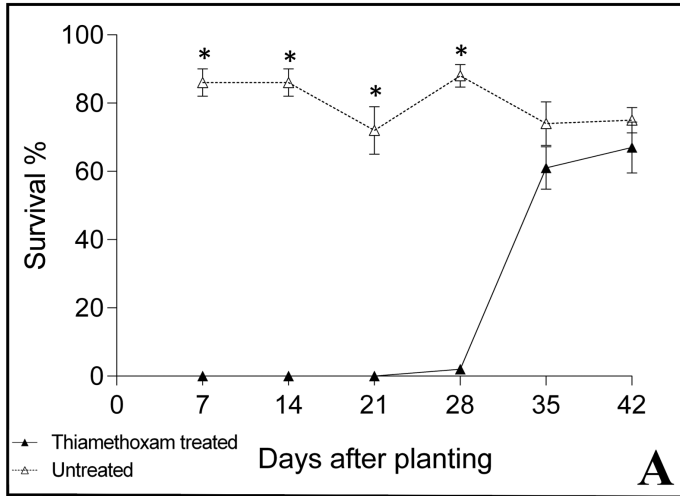

2016
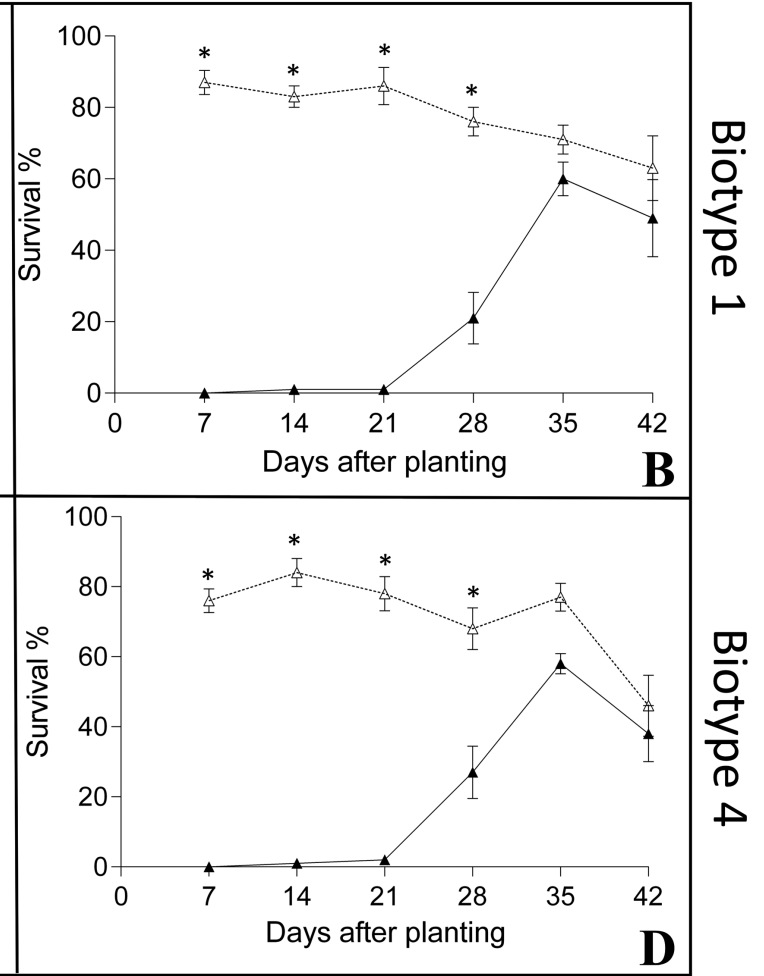

Fig. 1. Soybean plant age and soybean aphid survival in the greenhouse on plants grown from thiamethoxam-treated seeds (solid triangles) or untreated seeds (open triangles). Ten adult aphids were placed on plants at the time point indicated and survival assessed at $72 \mathrm{~h}$. (A and C) 2015 experiment; ( $\mathrm{B}$ and $\mathrm{D}$ ): 2016 experiment; ( $A$ and B): biotype 1 (Rag-susceptible) aphids; and ( $C$ and D): biotype 4 (Rag-resistant) aphids. Bars represent the standard error of the mean. Asterisks indicate significant differences between thiamethoxam-treated seeds and untreated plants based on Tukey's HSD ( $\alpha=0.05)$.

Table 1. ANOVA of aphid survival values in greenhouse, 2015 experiment

\begin{tabular}{|c|c|c|c|c|c|}
\hline Source of variation & df & Sum of squares & Mean squares & $F$ & $P$ \\
\hline Block & 1 & 0.9 & 0.9 & 0.42 & 0.5130 \\
\hline Plant age & 5 & 421.1 & 84.2 & 39.64 & $<0.0001$ \\
\hline Seed treatment & 1 & 2035.8 & 2035.8 & 958.22 & $<0.0001$ \\
\hline Biotype & 1 & 0.2 & 0.2 & 0.09 & 0.7569 \\
\hline Plant age $\times$ seed treatment & 5 & 546.5 & 109.3 & 51.44 & $<0.0001$ \\
\hline Seed treatment $\times$ Biotype & 1 & 0 & 0 & 0.01 & 0.8944 \\
\hline Plant age $\times$ Biotype & 5 & 25.4 & 5.1 & 2.39 & 0.038 \\
\hline Plant age $\times$ Seed treatment $\times$ Biotype & 5 & 12.7 & 2.5 & 1.19 & 0.3130 \\
\hline Residuals & 215 & 456.8 & 2.1 & & \\
\hline
\end{tabular}

$41.5 \%$. At $>35$ DAP, survival reached a plateau or decreased between 60 and $80 \%$ survival in biotype 1 and biotype 4 . Among years, the main effects 'plant age' and 'seed treatment' were all significant $(P<0.05)$, but no significant difference was observed between biotypes (Tables 1 and 2 ). The interaction effects 'plant age $\times$ seed treatment' were significant among years, whereas 'plant age $\times$ biotype' was significant only in 2015 . Survival on seed-treated soybean was significantly lower at 7-28 DAP for both biotype 1 and biotype 4 than on untreated soybean. At 35 DAP, however, only biotype 4 in 2015 still had lower survival on insecticidal seed-treated soybean $(P<0.05)$. At $42 \mathrm{DAP}$, any impact of thiamethoxam on aphid survival was negligible and not significantly different from untreated soybean in any of our greenhouse experiments.

\section{Field Experiment}

Generally, aphid survival in the field mirrored our greenhouse experiments, albeit with overall lower rates (Fig. 2). Due to slower plant emergence in the field, data collection started at 14 DAP. On untreated soybean, survival of biotype 1 ranged from 37 to $61 \%$ with a significant decreasing slope in response to plant age of $-0.2143 \pm$ $0.29(P<0.05)$, whereas survival in biotype 4 ranged from 45 to $80 \%$ with a significant positive slope of $0.9286 \pm 0.29(P<0.05)$ (Table 3$)$.

The increase in soybean aphid survival on seed-treated soybean was lower in the field study than in the greenhouse. At $28 \mathrm{DAP}$, survival of biotype 1 was $0.9 \% \pm 3.0$ (compared with $11.5 \% \pm 4.1$ in the greenhouse) and biotype 4 was $4.4 \% \pm 3.2$ (compared with $21 \%$ \pm 4.3 in the greenhouse). This difference persisted at $35 \mathrm{DAP}$, with an average of $2.2 \% \pm 2.1$ survival for biotype 1 (compared with $60.5 \%$ \pm 3.8 in the greenhouse) and $13.6 \% \pm 6.5$ for biotype 4 (compared with $52 \% \pm 3.9$ in the greenhouse). Surprisingly, aphid survival was significantly different among treated and untreated soybean at 42 DAP for biotype 4 . Survival of biotype 4 on treated soybean at 42 DAP was $25 \%$ lower compared with untreated soybean $(P<0.05$; Fig. 2). Significant interaction effects were detected for 'plant age $x$ 
Table 2. ANOVA of aphid survival values in greenhouse, 2016 experiment

\begin{tabular}{|c|c|c|c|c|c|}
\hline Source of variation & df & Sum of squares & Mean squares & $F$ & $P$ \\
\hline Block & 1 & 23.2 & 23.2 & 8.6 & 0.0035 \\
\hline Plant age & 5 & 187.2 & 37.4 & 14.0 & $<0.0001$ \\
\hline Seed treatment & 1 & 1690.7 & 1690.7 & 632.5 & $<0.0001$ \\
\hline Biotype & 1 & 7.7 & 7.7 & 2.8 & 0.0910 \\
\hline Plant age $\times$ Seed treatment & 5 & 567.2 & 113.4 & 42.4 & $<0.0001$ \\
\hline Seed treatment $\times$ Biotype & 1 & 4.0 & 4.0 & 1.4 & 0.2223 \\
\hline Plant age $\times$ Biotype & 5 & 16.7 & 3.3 & 1.2 & 0.2880 \\
\hline Plant age $\times$ Seed treatment $\times$ Biotype & 5 & 8.5 & 1.7 & 0.6 & 0.6741 \\
\hline Residuals & 215 & 574.7 & 2.7 & & \\
\hline
\end{tabular}

Table 3. Linear regression of aphid survival values (dependent variable) and DAP (independent covariant) on untreated soybean in greenhouse (2016 experiment) and field

\begin{tabular}{lccc}
\hline Soybean aphid biotype & df & Intercept \pm SE & Slope \pm SE \\
\hline $\begin{array}{l}\text { Greenhouse experiment, } 2016 \\
\text { Biotype 1 }\end{array}$ & 117 & $95.01 \pm 3.18$ & $-0.7082 \pm 0.13$ \\
Biotype 4 & 117 & $88.85 \pm 3.96$ & $-0.7082 \pm 0.13$ \\
Field experiment & & & \\
Biotype 1 & 96 & $53.80 \pm 12.42$ & $-0.2143 \pm 0.29$ \\
Biotype 4 & 96 & $37.80 \pm 8.78$ & $0.9286 \pm 0.29$ \\
\hline
\end{tabular}

biotype', 'seed treatment $\times$ plant age', and 'seed treatment $\times$ biotype', along with significant main effects for 'seed treatment', 'plant age', and 'biotype' $(P<0.05$; Table 4$)$. Mean separation on 'seed treatment $\times$ biotype' revealed that biotype 4 has higher survival than biotype 1 when aphids fed on untreated plants $(P<0.05)$, but not when fed on insecticidal seed-treated plants (Table 5).

\section{Thiamethoxam Concentration in Soybean}

In the greenhouse, thiamethoxam residues were $277.8 \mathrm{mg} / \mathrm{kg}$ at 7 DAP, decreasing to $22.8 \mathrm{mg} / \mathrm{kg}$ at 14 DAP and virtually undetectable levels at $\geq 28$ DAP (Fig. 3A). In soybean leaves from the field experiment, we measured thiamethoxam concentrations of $50.9 \mathrm{mg} /$ $\mathrm{kg}$ (Fig. 3B) at 14 DAP, to undetectable levels by $\geq 28$ DAP. Pearson's correlation between aphid survival and thiamethoxam residues from the greenhouse showed significant negative coefficients of -0.25 $(P=0.03)$. Correlation was also negative in the field $(-0.31)$, but not significant $(P=0.18)$. No thiamethoxam residues were detected in soybean plants grown from untreated (i.e., washed) seeds in greenhouse and field experiments.

\section{Discussion}

Using greenhouse and field experiments, we compared weekly soybean aphid survival on insecticidal seed-treated and untreated soybean over the course of 6 weeks. We also measured the weekly concentration of thiamethoxam to determine whether 1) the control of soybean aphid decreases quickly in time in accordance with the depletion of insecticide residues in plants and 2) the survivorship of virulent aphids on insecticidal seed-treated soybean differs from that of avirulent aphids. Our study demonstrated that insecticidal seed-treated soybean significantly reduced survival of aphid biotypes 1 and 4 up to 35 DAP, which correlates with a decrease of thiamethoxam in the plant tissues based on our UPLC-MS/MS analyses. Our study also determined that there was no difference in survivorship of aphid biotypes 1 and 4 on insecticidal seed-treated soybean plants; however, the virulent biotype 4 had higher survival on untreated soybean under field conditions. These findings provide new insights into the relatively short duration of seed treatment efficacy against the soybean aphid and two of its biotypes.

Much of the soybean acreage is now treated with seed treatment labeled for soybean aphid control (Douglas and Tooker 2015, Hurley and Mitchell 2017). By recording weekly aphid survival and measuring the concentration of thiamethoxam in soybean leaves, we showed that the increase in soybean aphid survival is related to the decrease in thiamethoxam concentration. Our data are consistent with other studies (McCornack and Ragsdale 2006, Seagraves and Lundgren 2012, Krupke et al. 2017), showing that aphid control is temporary, lasting between 35 and 42 DAP in both greenhouse and field experiments.

Despite the differences in conditions among greenhouses and field experiments, our data showed consistency. The greenhouse may represent the best-case scenario for protection by thiamethoxam. We controlled temperatures, daylight, supply of nutrients, and water. Interestingly, soybean aphid survival increased earlier (21-28 DAP) in the greenhouse experiments than the field experiments (35 DAP). This may be due to our constant watering in the greenhouse (e.g., drip irrigation), which possibly led to flushing the seed treatment from the soil faster. Indeed, thiamethoxam residues in greenhouse plants at 21 DAP were slightly lower $(5.4 \mathrm{mg} / \mathrm{kg})$ than on field plants $(9.9 \mathrm{mg} / \mathrm{kg})$. Alternatively, greenhouse conditions may have provided better conditions for soybean growth, enabling quicker metabolism of thiamethoxam and facilitating earlier increases in aphid survival. Soybean in the field could be stressed due to drier conditions and other abiotic/biotic factors, although throughout the course of the study, neither secondary insect infestations nor pathogens were observed. Nonetheless, by 42 DAP, no significant difference was observed in aphid survival among treated and untreated soybean in all experiments (with the exception of biotype 4 in the field, Fig. 2B). Based on our data and other studies, 35-42 DAP seems to be the limit for effective control of soybean aphid by thiamethoxam seed treatments. Assuming that most soybean in the North Central region are planted during the second to third week of May, thiamethoxam can provide protection until late June or early July.

The biology of the soybean aphid requires two to three generations on their primary host buckthorn (Rhamnus cathartica) before colonizing soybean (Bahlai et al. 2007, Welsman et al. 2007). Previous researchers have documented a 'phenological disjunction' (Ragsdale et al. 2004, Orantes et al. 2012) in the life history of the soybean aphid, where dispersal from buckthorn occurs with little to no soybean emerged. With no other known secondary plant host to colonize, dispersal from buckthorn causes seasonal bottlenecks (Orantes et al. 2012). However, in years with early planted soybean, there may be enough young soybean available for colonization. Indeed, soybean aphids have been collected from untreated soybean 


\section{Biotype 1}

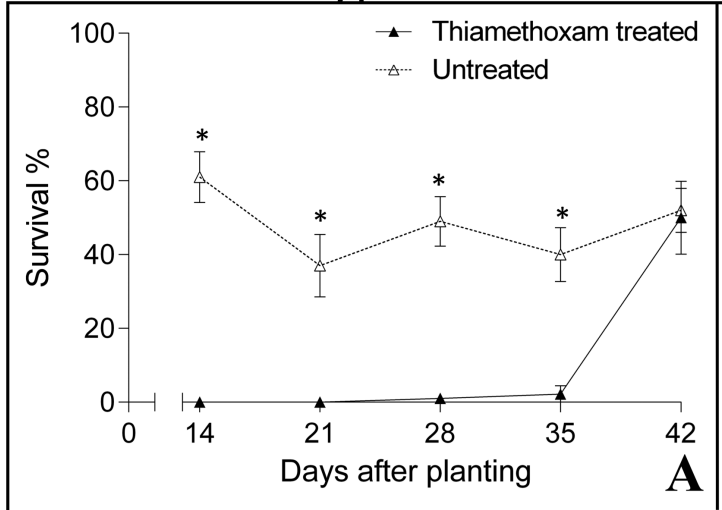

Biotype 4

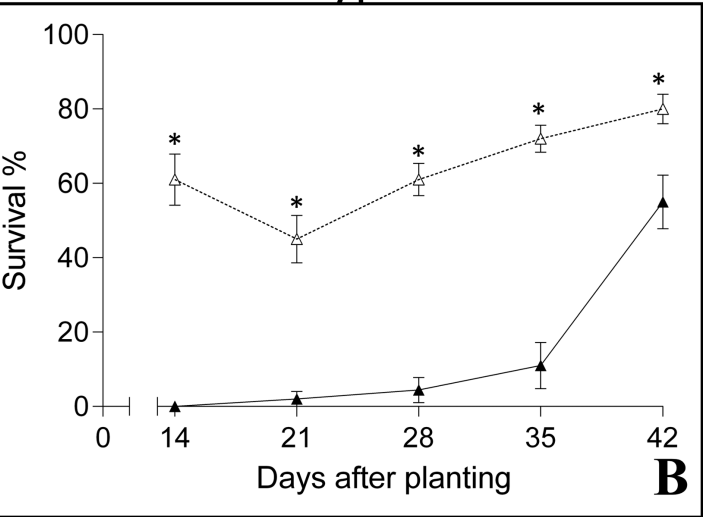

Fig. 2. Soybean plant age and soybean aphid survival in the field on plants grown from thiamethoxam-treated seeds (solid triangles) or untreated seeds (open triangles). Ten adult aphids were placed on plants at the time point indicated and survival assessed at $72 \mathrm{~h}$. (A) Survival of biotype 1 (Rag-susceptible) aphids, whereas part (B) Survival of biotype 4 (Rag-resistant) aphids. Bars represent the standard error of the mean. Asterisks indicate significant differences between thiamethoxam-treated seeds and untreated plants based on Tukey's HSD $(\alpha=0.05)$.

Table 4. ANOVA of aphid survival values in field experiment

\begin{tabular}{|c|c|c|c|c|c|}
\hline Source of variation & df & Sum of squares & Mean square & $F$ & $P$ \\
\hline Block & 9 & 38.6 & 4.2 & 1.73 & 0.2120 \\
\hline Seed treatment & 1 & 922.1 & 922.1 & 371.8 & $<0.0001$ \\
\hline Block $\times$ Seed treatment & 9 & 22.3 & 2.4 & 0.8 & 0.5850 \\
\hline Plant age & 4 & 339.6 & 84.9 & 28.5 & $<0.0001$ \\
\hline Biotype & 1 & 51.8 & 51.8 & 17.4 & $<0.0001$ \\
\hline Plant age $\times$ Biotype & 4 & 31.4 & 7.8 & 2.6 & 0.0357 \\
\hline Seed treatment $\times$ Plant age & 4 & 131.6 & 32.9 & 11.0 & $<0.0001$ \\
\hline Seed treatment $\times$ Biotype & 1 & 16.8 & 16.8 & 5.6 & 0.0186 \\
\hline Seed treatment $\times$ Plant age $\times$ Biotype & 4 & 9.3 & 2.3 & 0.78 & 0.5380 \\
\hline Residuals & 162 & 481.6 & 2.9 & & \\
\hline
\end{tabular}

Table 5. Survival values (in percentage) from field experiment with soybean aphid biotypes 1 and 4 on seed-treated or untreated soybean across all plant ages (14-42 DAP)

\begin{tabular}{lc}
\hline Treatments & Mean \pm SEM \\
\hline Biotype 4 on untreated soybean & $63.8 \pm 2.79 \mathrm{a}$ \\
Biotype 1 on untreated soybean & $47.8 \pm 3.28 \mathrm{~b}$ \\
Biotype 4 on treated soybean & $15.2 \pm 3.55 \mathrm{c}$ \\
Biotype 1 on treated soybean & $10.6 \pm 3.42 \mathrm{c}$ \\
\hline
\end{tabular}

Means followed by different letter are statistically distinct, Tukey's HSD $(\alpha=0.05)$.

as early as late-May in 2007 and June in 2008 (Orantes et al. 2012, Schmidt et al. 2012). Seed-treated soybean may extend this period of unsuitable hosts until first week of July, and therefore, it might help explain delays in peak soybean aphid population growth (Bahlai et al. 2015, Krupke et al. 2017). Yet, despite this delay, data from multiple locations and years across North Central Region show no economical benefit from the use of insecticidal seed treatment against soybean aphid (Krupke et al. 2017).

We also observed a delay in aphid response from the time when we detected the lowest concentration of thiamethoxam and the start of soybean aphid increase. By 28 DAP, we could not detect the presence of the insecticide in foliage. Yet, at 35 DAP, aphid survival was still significantly lower in treated than untreated soybean in the field and for biotype 4 in 2015 greenhouse experiment. Why soybean remains 'toxic' to these aphids is still unknown but may be related to our methods for measuring thiamethoxam. Similar delay between thiamethoxam concentration and increase in aphid survival was observed by Magalhaes et al. (2009), who estimated that thiamethoxam residues lasted up to 49 DAP, but aphid populations were significantly different from untreated at 65 DAP. Another possibility may be that the presence of thiamethoxam changes the biochemistry and physiology of soybean itself, providing limitations on soybean aphid growth, even when thiamethoxam is no longer present. Previous research on other plant-insect systems indicated changes of certain plant defense pathways when treated with neonicotinoids (Ford et al. 2010, Szczepaniec et al. 2013). Our data are consistent with other studies showing the impact of neonicotinoids altering plant physiology to the benefit of aphid control; however, we did not evaluate any impacts on nontarget or secondary soybean pests. Future studies on the impact of neonicotinoids on soybean physiology and control to other pests and off-targets are important, especially with Rag soybean.

In most cases, the effect of biotypes was not significant, suggesting that virulence does not impart increased survival on seed-treated aphid-susceptible soybean (i.e., no cross-resistance). However, on untreated soybean, biotype 4 had significantly higher survival than biotype 1. Varenhorst et al. (2015) documented a fitness cost of biotype 4 on susceptible plants, which was not apparent in our study with untreated and insecticidal seed-treated soybean. The lack of fitness costs is likely due to the variation in response of different varieties used 


\section{Greenhouse}

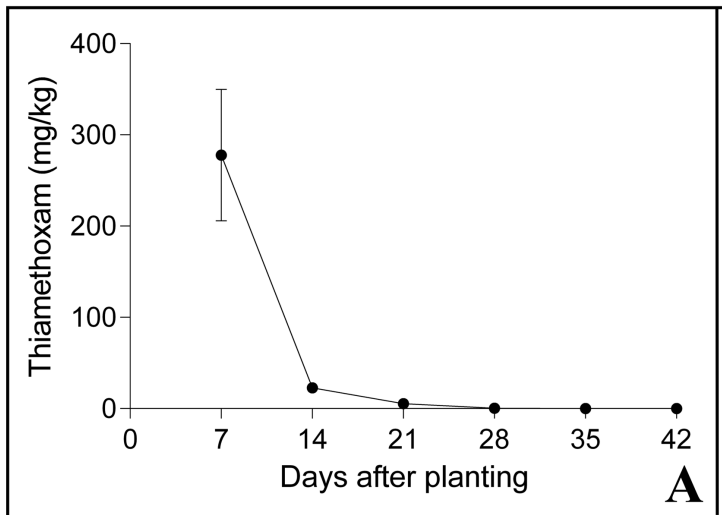

Field

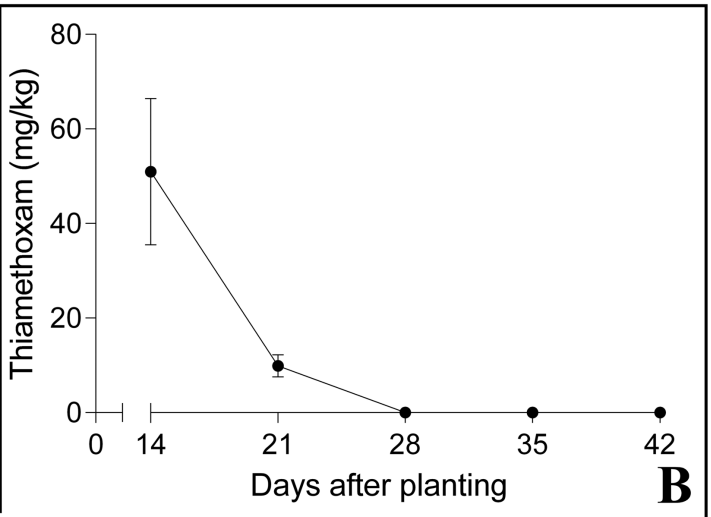

Fig. 3. Residues of thiamethoxam in insecticide seed treated soybean plant (in mg of a.i. per kg of dry weight of plant tissue) detected by the UPLC-MS/MS in greenhouse $(A)$ and field (B) experiments. Bars represent the standard error of the mean. (Note: No residues were detected for untreated soybean and therefore are not included; see Results).

among studies (susceptible isolines compared with agronomic/conventional soybean). Fitness costs are an important component to insect resistance management. Indeed, IRM models show that virulence can be managed, and durability of Rag resistance can be extended, in the presence of fitness costs (Varenhorst and O'Neal 2016). Given that both biotypes perform poorly on aphid susceptible soybean treated with thiamethoxam ( $<35 \mathrm{DAP})$, any refuge strategy to manage virulent biotypes cannot include treated susceptible soybean. However, if Rag soybean is treated in a blended refuge strategy, it may allow avirulent aphid populations to increase and establish earlier and quicker on untreated susceptible soybean, providing a greater ability to retain avirulence in the population. Early arriving aphids (as observed by Orantes et al. 2012 and Schmidt et al. 2012) could have a 3- to 4-wk advantage to establish and increase on untreated susceptible plants. With obviation of resistance (where infestation of a virulent biotype on Rag-soybean improves fitness of an avirulent biotype), we might then predict greater movement of avirulent aphids on untreated susceptible plants to Rag plants, competing with virulent aphids. However, in our case, biotype 4 had higher fitness than biotype 1 on untreated soybean. Future experiments are needed to fully understand fitness differences among soybean varieties, including those that contain $R a g$, and their interaction with insecticidal seed treatments. IRM modeling could explore this possibility, but results would have to be placed in context of the economic benefits, as insecticidal seed treatments are not likely to provide a return on investment of aphid control (Krupke et al. 2017) as well as impacts to the environment and/or nontarget organisms. The benefit of adding insecticidal seed treatments to Rag plants may not be worth the risk, especially since models show that single gene Rag resistance can be durable for $18 \mathrm{yr}$ and multiple gene Rag resistance can be reliable for $>25 \mathrm{yr}$ without them (Varenhorst et al. 2015). Additional research is necessary to understand the role, if any, of insecticidal seed treatments of IRM for extending Rag durability.

\section{Supplementary Data}

Supplementary data are available at Journal of Economic Entomology online.

\section{Acknowledgments}

We thank Nuris Acosta, Lucinda Wallace, Jenny Barnett (USDA-ARS), Natalie Fry, and Jim Hacker for their unconditional technical support throughout greenhouse and field experiments. In addition, we also acknowledge the financial support from the OARDC Seeds Grants, USDA-ARS National Program 304-Crop Protection and Quarantine (Project 3607-22000-012-00D), and the Ohio Soybean Council and by State and Federal fund appropriated to The Ohio State University/Ohio Agricultural Research and Development Center. Mention of trademarks or proprietary products does not constitute a guarantee or warranty of the product by OSU/OARDC or USDA-ARS and does not imply approval to the exclusion of other products that may also be suitable.

\section{References Cited}

Alt, J., and M. Ryan-Mahmutagic. 2013. Soybean aphid biotype 4 identified. Crop Sci. 53: 1491-1495.

Anastassiades, M., S. J. Lehotay, D. Stajnbaher, and F. J. Schenck. 2003. Fast and easy multiresidue method employing acetonitrile extraction/partitioning and "dispersive solid-phase extraction" for the determination of pesticide residues in produce. J. AOAC Int. 86: 412-431.

Bahlai, C. A., J. A. Welsman, A. W. Schaafsma, and M. K. Sears. 2007. Development of soybean aphid (Homoptera: Aphididae) on its primary overwintering host, Rhamnus cathartica. Environ. Entomol. 36: 998-1006.

Bahlai, C. A., W. van der Werf, W. vander Werf, M. O'Neal, L. Hemerik, and D. A. Landis. 2015. Shifts in dynamic regime of an invasive lady beetle are linked to the invasion and insecticidal management of its prey. Ecol. Appl. 25: 1807-1818.

Crowder, D. W., and Y. Carrière. 2009. Comparing the refuge strategy for managing the evolution of insect resistance under different reproductive strategies. J. Theor. Biol. 261: 423-430.

Douglas, M. R., and J. F. Tooker. 2015. Large-scale deployment of seed treatments has driven rapid increase in use of neonicotinoid insecticides and preemptive pest management in US field crops. Environ. Sci. Technol. 49: 5088-5097.

Fehr, W. R., C. E. Caviness, D. T. Burmood, and J. S. Pennington. 1971. Stage of development descriptions for soybean, Glycine max (L) Merrill. Crop Sci. 11: 929.

Ford, K. A., J. E. Casida, D. Chandran, A. G. Gulevich, R. A. Okrent, K. A. Durkin, R. Sarpong, E. M. Bunnelle, and M. C. Wildermuth. 2010. Neonicotinoid insecticides induce salicylate-associated plant defense responses. Proc. Natl. Acad. Sci. USA. 107: 17527-17532.

Gassmann, A. J., J. L. Petzold-Maxwell, R. S. Keweshan, and M. W. Dunbar. 2011. Field-evolved resistance to Bt maize by western corn rootworm. Plos One. 6: e22629.

Hanson, A. A., J. Menger-Anderson, C. Silverstein, B. D. Potter, I. V. MacRae, E. W. Hodgson, and R. L. Koch. 2017. Evidence for soybean aphid (Hemiptera: Aphididae) resistance to pyrethroid insecticides in the upper midwestern United States. J. Econ. Entomol. 110: 2235-2246. 
Hesler, L. S., M. V. Chiozza, M. E. O’Neal, G. C. MacIntosh, K. J. Tilmon, D. I. Chandrasena, N. A. Tinsley, S. R. Cianzio, A. C. Costamagna, E. M. Cullen, et al. 2013. Performance and prospects of Rag genes for management of soybean aphid. Entomol. Exp. Appl. 147: 201-216.

Hesler, L. S., K. C. Allen, R. G. Luttrell, T. W. Sappington, and S. K. Papiernik. 2018. Early-season pests of soybean in the United States and factors that affect their risk of infestation. J. Integr. Pest Manag. 9: 1-15.

Hill, C. B., L. Crull, T. K. Herman, D. J. Voegtlin, and G. L. Hartman. 2010. A new soybean aphid (Hemiptera: Aphididae) biotype identified. J. Econ. Entomol. 103: 509-515.

Hodgson, E. W., B. P. McCornack, K. Tilmon, and J. J. Knodel. 2012. Management recommendations for soybean aphid (Hemiptera: Aphididae) in the United States. J. Integr. Pest Manag. 3: E1-E10.

Horwitz, W. 2000. Official methods of analysis of AOAC International, 17th ed. AOAC International, Gaithersburg, MD.

Hummel, N. A., A. Meszaros, D. R. Ring, J. M. Beuzelin, and M. J. Stout. 2014. Evaluation of seed treatment insecticides for management of the rice water weevil, Lissorhoptrus oryzophilus Kuschel (Coleoptera: Curculionidae), in commercial rice fields in Louisiana. Crop Prot. 65: 37-42.

Hurley, T., and P. Mitchell. 2017. Value of neonicotinoid seed treatments to US soybean farmers. Pest Manag. Sci. 73: 102-112.

Kim, K. S., C. B. Hill, G. L. Hartman, M. A. R. Mian, and B. W. Diers. 2008. Discovery of soybean aphid biotypes. Crop Sci. 48: 923-928.

Koch, R. L., E. W. Hodgson, J. J. Knodel, A. J. Varenhorst, and B. D. Potter. 2018. Management of insecticide-resistant soybean aphids in the upper midwest of the United States. J. Integr. Pest Manag. 9: 1-7.

Krell, R. K., L. P. Pedigo, J. H. Hill, and M. E. Rice. 2004. Bean leaf beetle (Coleoptera: Chrysomelidae) management for reduction of bean pod mottle virus. J. Econ. Entomol. 97: 192-202.

Krupke, C. H., A. M. Alford, E. M. Cullen, E. W. Hodgson, J. J. Knodel, B. McCornack, B. D. Potter, M. I. Spigler, K. Tilmon, and K. Welch. 2017. Assessing the value and pest management window provided by neonicotinoid seed treatments for management of soybean aphid (Aphis glycines Matsumura) in the Upper Midwestern United States. Pest Manag. Sci. 73: 2184-2193.

Magalhaes, L. C., T. E. Hunt, and B. D. Siegfried. 2009. Efficacy of neonicotinoid seed treatments to reduce soybean aphid populations under field and controlled conditions in Nebraska. J. Econ. Entomol. 102: 187-195.

McCarville, M. T., and M. E. O’Neal. 2013. Soybean aphid (Aphididae: Hemiptera) population growth as affected by host plant resistance and an insecticidal seed treatment. J. Econ. Entomol. 106: 1302-1309.

McCarville, M., E. W. Hodgson, M. O'Neal; Iowa State University. University Extension., and Iowa Soybean Association. 2012. Soybean aphid-resistant soybean varieties for Iowa. Iowa State University Extension and Outreach, Ames, IA.

McCornack, B., and D. W. Ragsdale. 2006. Efficacy of thiamethoxam to suppress soybean aphid populations in Minnesota soybean crop management. Crop Manag. 102: 187-195.

Orantes, L. C., W. Zhang, M. A. Mian, and A. P. Michel. 2012. Maintaining genetic diversity and population panmixia through dispersal and not gene flow in a holocyclic heteroecious aphid species. Heredity (Edinb). 109: $127-134$.

Petzold-Maxwell, J. L., L. J. Meinke, M. E. Gray, R. E. Estes, and A. J. Gassmann. 2013. Effect of Bt maize and soil insecticides on yield, injury, and rootworm survival: implications for resistance management. J. Econ. Entomol. 106: 1941-1951.
Ragsdale, D. W., D. J. Voegtlin, and R. J. O’Neil. 2004. Soybean aphid biology in North America. Ann. Entomol. Soc. Am. 97: 204-208.

Ragsdale, D. W., B. P. McCornack, R. C. Venette, B. D. Potter, I. V. MacRae, E. W. Hodgson, M. E. O'Neal, K. D. Johnson, R. J. O'Neil, C. D. DiFonzo, et al. 2007. Economic threshold for soybean aphid (Hemiptera: Aphididae). J. Econ. Entomol. 100: 1258-1267.

Ragsdale, D. W., D. A. Landis, J. Brodeur, G. E. Heimpel, and N. Desneux. 2011. Ecology and management of the soybean aphid in North America. Annu. Rev. Entomol. 56: 375-399.

Roush, R. T. 1998. Two-toxin strategies for management of insecticidal transgenic crops: can pyramiding succeed where pesticide mixtures have not? Philos. T. Roy. Soc. B. 353: 1777-1786.

Rutledge, C. E., and R. J. O'Neil. 2006. Soybean plant stage and population growth of soybean aphid. J. Econ. Entomol. 99: 60-66.

Schmidt, N. P., M. E. O’Neal, P. F. Anderson, D. Lagos, D. Voegtlin, W. Bailey, P. Caragea, E. Cullen, C. DiFonzo, K. Elliott, et al. 2012. Spatial distribution of Aphis glycines (Hemiptera: Aphididae): a summary of the suction trap network. J. Econ. Entomol. 105: 259-271.

Schmidt-Jeffris, R. A., and B. A. Nault. 2016. Anthranilic diamide insecticides delivered via multiple approaches to control vegetable pests: a case study in snap bean. J. Econ. Entomol. 109: 2479-2488.

Seagraves, M. P., and J. G. Lundgren. 2012. Effects of neonicotinoid seed treatments on soybean aphid and its natural enemies. J. Pest Sci. 85: 125-132.

Szczepaniec, A., M. J. Raupp, R. D. Parker, D. Kerns, and M. D. Eubanks. 2013. Neonicotinoid insecticides alter induced defenses and increase susceptibility to spider mites in distantly related crop plants. Plos One. 8: e62620.

Tilmon, K. J., E. W. Hodgson, M. E. O’Neal, and D. W. Ragsdale. 2011. Biology of the soybean aphid, Aphis glycines (Hemiptera: Aphididae) in the United States. J. Integr. Pest Manag. 2: 1-7.

(USGS) United States Geological Survey. 2014. Project: estimated annual agricultural pesticide use maps-thiamethoxam, pesticide natioanl synthesis project. https://water.usgs.gov/nawqa/pnsp/usage/maps/show_map.php? year=2015\&map=THIAMETHOXAM\&hilo=L\&disp=Thiamethoxam

Varenhorst, A. J., and M. E. O'Neal. 2016. The effect of an interspersed refuge on Aphis glycines (Hemiptera: Aphididae), their natural enemies, and biological control. J. Econ. Entomol. 109: 406-415.

Varenhorst, A. J., M. T. McCarville, and M. E. O’Neal. 2015. Reduced fitness of virulent Aphis glycines (Hemiptera: Aphididae) biotypes may influence the longevity of resistance genes in soybean. Plos One. 10: e0138252.

Welsman, J. A., C. A. Bahlai, M. K. Sears, and A. W. Schaafsma. 2007. Decline of soybean aphid (Homoptera: Aphididae) egg populations from autumn to spring on the primary host, Rhamnus cathartica. Environ. Entomol. 36: 541-548.

Wilde, G. E., R. J. Whitworth, M. Claassen, and R. A. Shufran. 2001. Seed treatment for control of wheat insects and its effect on yield. J. Agr. Urban Entomol. 18: 1-11.

Wilde, G., K. Roozeboom, M. Claassen, K. Janssen, and M. Witt. 2004. Seed treatment for control of early-season pests of corn and its effect on yield. J. Agr. Urban Entomol. 21: 75-85.

Wilde, G., K. Roozeboom, A. Ahmad, M. Claassen, B. Gordon, W. Heer, L. Maddux, V. Martin, P. Evans, K. Kofoid, et al. 2007. Seed treatment effects on early-season pests of corn and on corn growth and yield in the absence of insect pests. J. of Agr. Urban Entomol. 24: 177-193. 